\title{
Cynegetic Restoration
}

\author{
"To enter the river and attempt to bring \\ this strong creature out of its own medium alive \\ and uninjured is an opportunity to experience \\ a momentary parity between human and salmon, \\ mediated by slippery rock and swift current."
}

-Freeman House

$\mathrm{N}_{\mathrm{dat}}^{\mathrm{ot}}$

ot long ago I had an interesting conversation with Jim Addis, head of the Division of Resources Management for the Wisconsin Department of Natural Resources, on the subject of ecological restoration and its application to his own work.

As administrator for his division, Addis is responsible for management of roughly 400,000 hectares of agency holdings, including 80,000 hectares of natural areas, and he told me that he and his colleagues elsewhere who have similar responsibilities are increasingly concerned about evidence that hunting is declining in popularity, at least in some parts of the United States. He said that several studies of sales of licenses, ammunition, and the like suggest that the number of hunters taking to the field is declining in several states, and that there is probably a decline at least in the percentage of the population taking up hunting nationally. (Participation in fishing, in contrast, seems to be holding about steady.)

Presumably, this reflects a change in habits as more and more Americans move off farms and into towns and cities. In any event, some conservationists are concerned about this, Addis told me, because hunters (and anglers) have made up one of the strongest constituencies for conservation since the days of Teddy Roosevelt.

Some may suppose that it is good that hunters are a dwindling breed, and that their decline represents a kind of cultural maturing, an advance beyond the barbarism of blood sport and the idea of nature as resource. Others, like Jim Addis and I, see it not as maturation so much as a mere diversion of interest to more urban pursuits-yet another sign of alienation from nature. And our doubts are supported by thinking such as that of Paul Shepard, who argues (in books like The Tender Carnivore and The Sacred Game) that humans are essentially hunters, and that a healthy culture provides an outlet for the cynegetic, or hunting, instinct.

The income from sales of licenses and other equipment is not the real point. The real point is that this willingness to pay suggests that hunters (like anglers, mushroom gatherers, and others who are carrying out the classic human business of hunting and gathering in the woods and fields) typically develop a powerful attachment to these ecosystems-attachments that may be impossible to develop in any other way.

If this is so, the question is what might take the place of these activities? What kinds of experience out in the field might replace them as popular ways of engaging nature on its own terms, participating in its relationships of predator and prey, its cycles of birth and death?

Traditional non-consumptive activities such as hiking, birding, and photography may be part of the answer. These activities, however, appeal only to people with particular tastes, and none offers the dramatic intensity - and the essential tragic experience-of hunting.

Moreover, Addis points out that a recent study commissioned by his office indicated that "non-consumptive" users of nature are less likely than the "gatherers" to dig into their pockets to support conservation programs.

Addis was intrigued by the notion that restoration might provide part of the answer-that it may be a way of getting large numbers of people back out in the woods, engaging in experiences that really satisfy the hunter and gatherer in us, creating inhabitants of the natural landscape who will also be advocates for its conservation.

I find this a highly plausible notion, and in fact have come to regard restoration as the popular outdoor activity of the future-the way people in the 21 st Century will "use" nature, the experience that will to a large extent define their relationship with it.

One reason why I believe this is obvious: restoration incorporates virtually the whole range of human experiences of nature, the many ways different people with various cultures, tastes, pred- 
ilections, and ways of life have approached the natural landscape. Thus, as I have pointed out before, restoration entails birding, botanizing, hiking, and boating; but it also entails gardening and doing science-and hunting.

In addition, the work of restoration effectively changes the sign of our relationship from negative to positive. While there are room and resources for only so many hunters, gatherers or birders - think of a thousand Thoreaus at Walden Pond-there is room for any number of restorationists. In fact, the more the better.

Restoration includes hunting in several ways. Most conspicuously and dramatically, the restorationist may hunt to fulfill the role of a missing predator in order to control populations of prey species. Here the restorationist actually joins forces with the traditional hunter, since the regulation of hunting to manage game and game habitat is a traditional conservation measure that has at times been used in a restorative manner.

Less dramatic than hunting to kill in the traditional manner, but probably more important as a component of the experience of most restorationists, is another kind of hunting-hunting merely to observe, to study, to census, and perhaps to capture in order to breed, rear, and reintroduce.
I am thinking here of the experience of restorationists like Freeman House with the Mattole River restoration project in California (quoted above, from an article in Whole Earth Review, Spring 1990, page 38), or like Ron Panzer of Chicago, who is pioneering the study of insects in restored prairies. Panzer spends a good deal of time searching for bugs in the grass, and especially for some of the rarer moths and butterflies, which he sometimes captures and breeds to provide individuals for reintroduction efforts.

Of course, whether this kind of experience really is similar, psychologically and spiritually, to the experience of hunting in more traditional ways is an open question.

Can the experience of the hunt really be disengaged from the climactic act of killing, with all its tragic overtones? Listening to Panzer talk about his experience I have felt that it must come close to the experience of the hunter, the "alert man" described by Ortega y Gasset in his classic Meditations on Hunting.

Figuring out whether that is true is a task for the restorationist. I recommend it to anyone who is interested, and would be delighted to learn the results.

William R. Jordan III 